\title{
Tracing GFP-labeled WJMSCs in vivo using a chronic salpingitis model: an animal experiment
}

\author{
Zhe $\mathrm{Li}^{1 \dagger}$, Zhao Zhang ${ }^{1,2+}$, Wai-kit Ming ${ }^{1,3}$, Xin Chen $^{1}$ and Xiao-min Xiao ${ }^{1 *}$
}

\begin{abstract}
Background: The present study was conducted to evaluate the distribution of Wharton's jelly-derived mesenchymal stem cells (WJMSCS) and their repairing function on the oviduct.

Methods: WJMSCs were transfected with the LV3-GFP-PURO lentivirus. Female New Zealand rabbits $(n=24)$ were divided randomly into control $\mathrm{A}$ and $\mathrm{B}$ groups and experimental $\mathrm{C}$ and $\mathrm{D}$ groups to establish inflammation models. Sterile saline solution or WJMSCs were injected into rabbits via ear veins and/or genital tract perfusion once weekly for 3 weeks. All rabbits were humanely sacrificed 1 week after the last perfusion to collect the oviduct, uterus, liver, and bladder for examination. Green fluorescent protein (GFP) and cytokeratin 7 (CK7) were imaged using a Leica Qwin Plus V3 fluorescence confocal microscope and analyzed as mean optical densities in an Image-Pro Plus analysis system.
\end{abstract}

Results: We found that lentivirus expressing the GFP gene produced an efficient transfection. The mean optical density values of GFP and CK7 in the oviducts were higher in the experimental D group than those in the control A and experimental C groups. No GFP fluorescence deposits occurred in the bladder of the control A group or experimental C group. Colocalization of CK7 and WJMSCs was observed in the oviducts in all groups.

Conclusions: WJMSCs exhibited homing characteristics and migrated to the injured oviduct to promote epithelial cell growth. Additionally, local treatment resulted in higher efficiency.

Keywords: Green fluorescent protein, Wharton's jelly-derived mesenchymal stem cells, Tracing, Oviducts, Transformation

\section{Background}

Tubal infertility has long been considered the major cause of female infertility. Salpingitis and/or pelvic inflammation caused by infection is one of the most important factors of tubal infertility. Severe salpingitis may damage the fallopian tube mucosa, and pelvic inflammation damages the structure of the oviduct, which may result in fimbria adhesion, distal tube obstruction, and hydrosalpinx [1]. However, current treatment methods cannot fix the tube injury. Therefore, new methods to repair the reproduction function of the oviduct are required to allow gametes to combine and grow in vivo under natural circumstances.

Mesenchymal stem cells (MSCs) [2] are used in cell therapy and regenerative medicine because these cells are

\footnotetext{
* Correspondence: jnuxiaoxiaomin@163.com

${ }^{\dagger}$ Equal contributors

${ }^{1}$ The Department of Obstetrics and Gynecology, 1st Affiliated Hospital of Jinan University, Guangzhou 510000, China

Full list of author information is available at the end of the article
}

easily isolated and acquired, exhibit rapid expansion in culture, can be used in autologous transplantation, and exhibit significant paracrine effects [3]. Wharton's jellyderived mesenchymal stem cells (WJMSCs) possess distinct advantages, such as accessibility, painless donation procedures, and high separation rates [4]. Moreover, WJMSCs do not express main histocompatibility complex (MHC) II [5] and exhibit low immunogenicity and little or no expression of MHC I [6]. WJMSCs exhibit a higher proliferation capacity and lower expression of CD106, HLA-ABC, and HLA-DR than MSCs from bone [7, 8]. Previous studies have shown that WJMSCs could survive in vivo for a comparatively long time after engraftment [9-11], due to their ability to modulate the immunological response contributing to WJMSC viability $[12,13]$.

Therefore, our study established a chronic salpingitis model in New Zealand rabbits and transplanted WJMSCs expressing green fluorescent protein (GFP) 
using different methods to evaluate the distribution of these stem cells. Our hope is that the findings from this study will further inform and guide the future clinical use of WJMSCs to treat tubal infertility in women.

\section{Methods}

Isolation, culture, and identification of WJMSCs

Human umbilical cord tissue was obtained from healthy and full-term infants who were born via social-factor caesarean section. HbsAg, anti-HIV, CMV-IgM, syphilis, mycoplasma, and chlamydia tests were negative. The umbilical cord tissue was washed with D-Hanks BSS. Umbilical veins, the umbilical artery, and the outer membrane of the umbilical tissue were dislodged. Wharton's jelly was removed and cut into $1 \mathrm{~mm} \times 1 \mathrm{~mm} \times 1 \mathrm{~mm}$ tissue blocks. These tissue blocks were resuspended in $0.075 \%$ type I collagenase and incubated at $37^{\circ} \mathrm{C}$ for $10-14 \mathrm{~h}$ with magnetic stirrers. The digested mixture was washed and diluted in D-Hanks BSS, and the suspensions were centrifuged at $1500 \mathrm{rpm}$ for $5 \mathrm{~min}$ at room temperature to obtain a cell pellet. The pellet was washed and centrifuged three times in D-Hanks BSS. The pellet was washed and resuspended in growth medium containing DMEM and $10 \%$ FBS and was cultured in $5 \% \mathrm{CO}_{2}$ in a $37{ }^{\circ} \mathrm{C}$ incubator. The growth medium was renewed every 3 days. Cells that adhered to the wall were fusiform fibroblasts and were $80 \%$ fused in approximately 1 week. Flow cytometry was used to detect the presence of CD73, CD90, and CD105 and the absence of CD34 and CD45 to determine which cells were WJMSCs. The cell viability in our study was $95-98 \%$, and cells were diluted with a sterile saline solution to $1 \times 10^{6} / \mathrm{ml}$ on the day of study. All of these materials were manufactured and provided by the Cord Blood Bank of Guangdong Province of China on the day of use.

\section{Model-making bacterial strain}

A lyophilized (ATCC25922) strain was inoculated in a fresh beef infusion broth and cultured in an incubator $\left(37{ }^{\circ} \mathrm{C}\right)$ for $24 \mathrm{~h}$. The mixture was centrifuged at $1000 \mathrm{rpm}$ for $10 \mathrm{~min}$ at room temperature to obtain precipitates. The precipitates were washed three times in PBS and diluted with a sterile saline solution to a $3 \times 10^{8} / \mathrm{ml}$ Escherichia coli suspension.

\section{Establishment of the animal model in pre-experiments}

As our previous work demonstrated before, the transvaginal intrauterine administration of a $3 \times 10^{8} / \mathrm{ml}$ Escherichia coli suspension was sufficient to establish a chronic salpingitis model in female New Zealand rabbits. Salpingitis became a chronic inflammatory condition in 15 days [14].

\section{Experimental animals and grouping}

Twenty-four pathogen-free female New Zealand rabbits (4-5 months old, nonpregnant, weighing $2.5 \mathrm{~kg} \pm 250 \mathrm{~g}$ ) were provided by the Animal Experiment Center of Guangzhou University of Chinese Medicine (qualification no. CV20130015). All experimental animals were divided equally into two groups: a control group and an experimental group. All female rabbits were injected with $80 \mathrm{IU}$ of HCG to synchronize the estrous cycles. Female rabbits in the experimental group were anesthetized using pentobarbital sodium. Disposable sterile newborn sputum suction tubes were inserted into the urogenital tract to instill an $E$. coli suspension into the uterine cavity to establish the chronic salpingitis model.

Rabbits in the control group $(n=12)$ were divided randomly into A and B groups. Fifteen days after HCG injections, rabbits in the control A group $(n=6)$ were injected with $0.5 \mathrm{ml}$ of a $1 \times 10^{6} / \mathrm{ml}$ GFP-labeled WJMSC suspension via the ear vein. Disposable sterile newborn sputum suction tubes were inserted into the urogenital tract of rabbits to instill $0.5 \mathrm{ml}$ of a $1 \times 10^{6} / \mathrm{ml}$ GFPlabeled WJMSC suspension. This procedure was executed once weekly for 3 weeks. Rabbits in the control B group $(n=6)$ received $1.0 \mathrm{ml}$ of a $1 \times 10^{6} / \mathrm{ml}$ GFP-marked WJMSC suspension via the urogenital tract. This procedure was also executed once weekly for 3 weeks [15-20]. All 12 rabbits were humanely sacrificed 1 week after the last WJMSC perfusion, and the oviduct, uterus, bladder, and liver were sampled for examination.

Experimental groups $(n=12)$ were perfused with an $E$. coli suspension and divided randomly into $C$ and $D$ groups. Fifteen days after intubation, rabbits in the experimental $\mathrm{C}$ group were injected with $0.5 \mathrm{ml}$ of a $1 \times 10^{6} / \mathrm{ml}$ suspension of GFP-marked WJMSCs, via the ear vein. Disposable sterile newborn sputum suction tubes were inserted into the urogenital tract of rabbits to perfuse $0.5 \mathrm{ml}$ of a $1 \times 10^{6} / \mathrm{ml}$ suspension of GFP-labeled WJMSCs. This procedure was executed once weekly for 3 weeks. Rabbits in the experimental D group received $1.0 \mathrm{ml}$ of a $1 \times 10^{6} / \mathrm{ml}$ suspension of GFP-labeled WJMSCs via the urogenital tract. This procedure was also executed once weekly for 3 weeks. All 12 rabbits were humanely sacrificed 1 week after the last WJMSC perfusion, and the oviduct, uterus, bladder, and liver were sampled for examination.

One female rabbit in the control group died on the 20th day of the experiment, and one female rabbit in the experimental group died on the 23rd day of the experiment. The other 22 rabbits exhibited normal appearance and vaginal secretions. No antibiotics or drugs were administered during the experimental period.

\section{Cell transfection and transfection efficiency}

The LV3-GFP-PURO lentivirus $\left(5 \times 10^{9} \mathrm{TU} / \mathrm{ml}\right)$ was purchased from GenePharma (China). WJMSCs were inoculated into two plates with six wells each 1 day before transfection. Each well contained $2 \times 10^{5}$ 
WJMSCs. When the cells reached $70-80 \%$ confluence, the complete medium (DMEM-high glucose $+10 \%$ FBS) was removed. WJMSCs were then transfected with LV3-GFP-PURO lentivirus $\left(5 \times 10^{9} \mathrm{TU} / \mathrm{ml}\right.$ at 100,200 , and $400 \mathrm{MOI}$ in the presence of $5 \mu \mathrm{g} / \mathrm{ml}$ polybrene and complete medium). GFP was measured using flow cytometry at $96 \mathrm{~h}$ to evaluate transfection efficiency.

\section{Assessment of cell proliferation ability}

Assessment of WJMSC proliferation ability was performed using the MTT assay. WJMSCs were inoculated into four plates with 96 wells per plate. Each well contained a density of $2 \times 10^{5}$ WJMSCs. The WJMSCs were divided into transfer and untransfected groups. The 96-well plates were placed in an incubator at $5 \% \mathrm{CO}_{2}$ at a temperature of $37{ }^{\circ} \mathrm{C}$ overnight. WJMSCs in the transfer group were transfected with LV3-GFP-PURO lentivirus $\left(5 \times 10^{9} \mathrm{TU} / \mathrm{ml}\right)$ at $200 \mathrm{MOI}$ based on the results of transfection efficiency, and WJMSCs in the untransfected group received an equivalent dose of PBS. Each group had five parallel wells. Cells in one of the four plates were incubated with the MTT solution for $4 \mathrm{~h}$ at $24,48,72$, and $96 \mathrm{~h}$ after transfection. The medium was removed, and $150 \mu \mathrm{l}$ of dimethylsulfoxide was added to each well. Absorbance was measured at $490 \mathrm{~nm}$ using a Model 680 microplate reader.

\section{GFP-labeled WJMSC suspensions}

WJMSCs transfected with lentivirus at 200 MOI for $96 \mathrm{~h}$ were cultured in selection medium (DMEM-high glucose $+10 \% \mathrm{FBS}+2 \mu \mathrm{g} / \mathrm{ml}$ puromycin) to select positive cells. Untransfected cells were washed away 1 day after selection, and transfected cells were cultured in new selection media. The remaining cells were cultured in normal media 2 days after the second selection. Cells were cultured to $80-90 \%$ confluence, and the transfected WJMSCs were trypsinized and diluted with a sterile saline solution to $1 \times 10^{6} / \mathrm{ml}$ for experimental use.

\section{Frozen sectioning and immunofluorescent staining}

Fresh tissue cryosections $(3-4 \mu \mathrm{m})$ were embedded in optimum cutting temperature compound gel and fixed for $10 \mathrm{~min}$ in $4{ }^{\circ} \mathrm{C}$ acetone.

Sections were then washed in PBS three times for 5 min. CK7 (1:100) primary antibodies were added to sections and incubated at $37^{\circ} \mathrm{C}$ in an incubator for $1 \mathrm{~h}$.

Afterwards, sections were washed three times in PBS. Fluorogenic secondary antibodies were added to sections and incubated at $37{ }^{\circ} \mathrm{C}$ for $1 \mathrm{~h}$.

Sections were then washed again in PBS and mounted in Fluoromount-G. Stained sections were imaged using a Leica Qwin Plus V3 fluorescence confocal microscope and analyzed as mean optical densities (MODs) in an Image-Pro Plus analysis system.

\section{Statistical methods}

All data are presented as the mean \pm standard error. Assessments of cell proliferation ability were analyzed using independent-sample $t$ tests, and $P<0.05$ was considered statistically significant. Other outcomes were analyzed using one-way-ANOVA and the least-significant difference test (homogeneity of variance) or Tamhane's T2 test (heterogeneity of variance). All data were analyzed using SPSS 13.0 statistical software (SPSS, Inc., Chicago, IL, USA).

\section{Results}

Assessment of transfection efficiency of LV3-GFP-Puro lentivirus in vitro

Cells were transduced with LV3-GFP-PURO lentivirus $\left(5 \times 10^{9} \mathrm{TU} / \mathrm{ml}\right)$ at 100,200 , and $400 \mathrm{MOI}$ for $96 \mathrm{~h}$, and all WJMSCs expressed green fluorescence. Fluorescence intensity increased with increasing MOI values. Flow cytometry demonstrated that the transfection efficiency was $34.5 \%$ at $100 \mathrm{MOI}, 96.7 \%$ at $200 \mathrm{MOI}$, and $96.5 \%$ at 400 MOI. Optimal transfection efficiency of LV3-GFPPuro lentivirus occurred at $200 \mathrm{MOI}$, and $200 \mathrm{MOI}$ was therefore used in subsequent experiments (Fig. 1).

\section{Assessment of cell proliferation ability in vitro}

Assessment of WJMSC proliferation ability was performed using the MTT assay. The results demonstrated that the cell proliferation ability of WJMSCs in the transfected group and the untransfected group was not significantly different at any time (Table 1 ).

\section{Tracking of WJMSCs in vivo MOD of GFP in rabbit oviducts}

GFP fluorescence deposits occurred in the epithelia of the oviduct. There were no deposits in mesenchymal or muscular layers. One-way ANOVA and Tamhane's T2 test (heterogeneity of variance, $P<0.05$ ) were performed to examine the MOD values of GFP in the oviducts of different groups. The MOD values of GFP in the oviducts of the different groups were significantly different $(P<0.05)$. MOD values of GFP in the experimental D group were higher than in the control A group and experimental $C$ group $(P=0.037, P=0.047)$. No significant difference were found between the control A group and the experimental $C$ group $(P=0.147)$ (Fig. 2, Table 2).

\section{MOD of GFP in rabbit uteri}

GFP fluorescence deposits occurred in epithelial cells in the endometrium. There were no deposits in the muscular layer. Two rabbits in the control A group had no fluorescence deposits in the endometrium. One-way ANOVA revealed that the MOD values of GFP in the uteri of different groups were not significantly different $(P=0.217)$ (Fig. 3, Table 2$)$. 

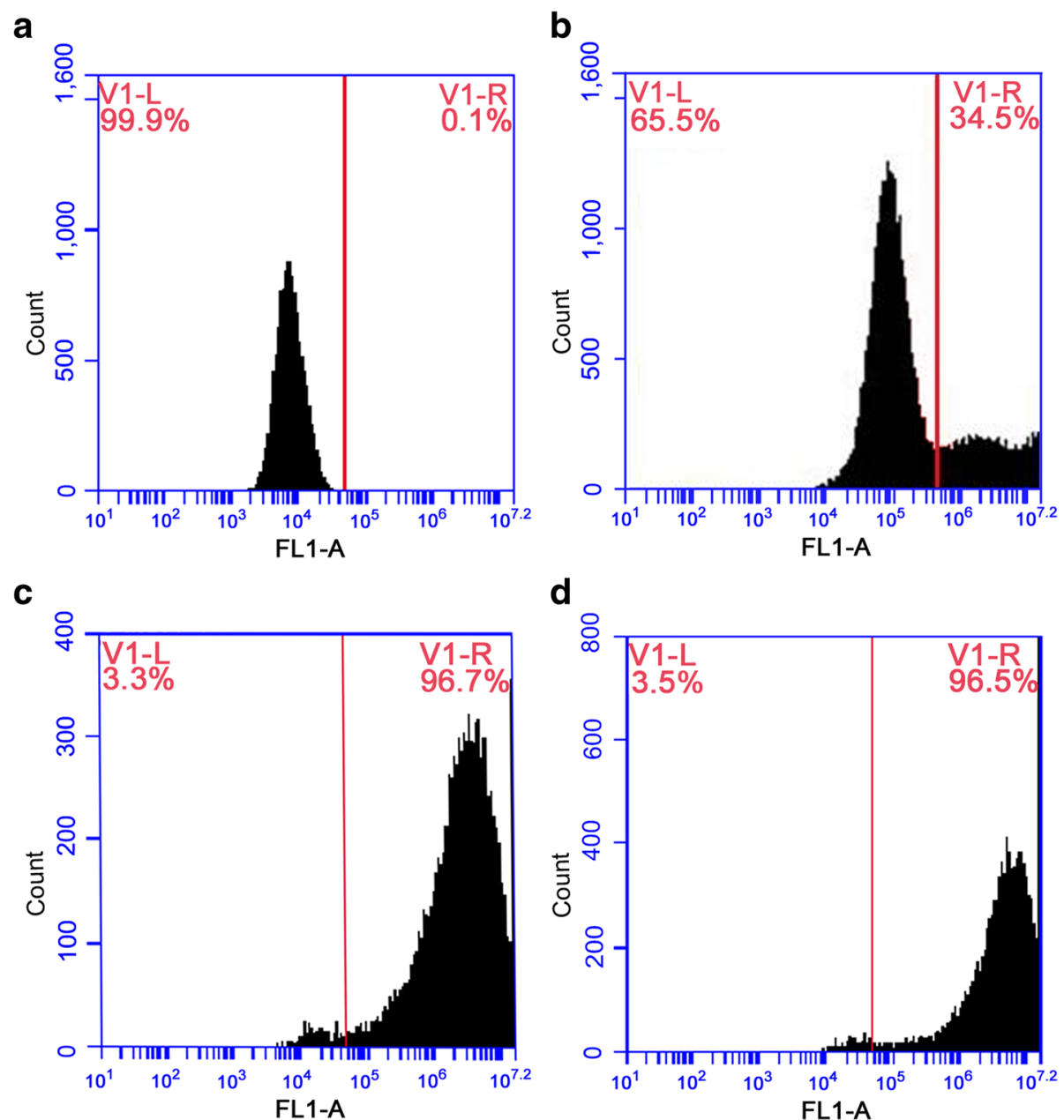

Fig. 1 Assessment of transfection efficiency using flow cytometry. a Untransfected cells. b Transfection of cells at MOI = 100. c Transfection of cells at $\mathrm{MOI}=200$. $\mathbf{d}$ Transfection of cells at $\mathrm{MOI}=400$

\section{MOD of GFP in rabbit bladders}

GFP fluorescence deposits occurred in the epithelia of the bladder. No GFP fluorescence deposits occurred in the control A group or experimental C group. One-way ANOVA and Tamhane's T2 test (heterogeneity of variance, $P<0.05$ ) revealed that the MOD values of GFP in the bladders of different groups were significantly different $(P<0.05)$ (Fig. 4 , Table 2).

\section{MOD of GFP in rabbit livers}

GFP fluorescence deposits occurred in hepatic cells. One-way ANOVA revealed that the MOD values of GFP in the livers of different groups were not significantly different $(P=0.176)$ (Fig. 5, Table 2).

\section{MOD of GFP in four organs of rabbits in each group}

In the control $\mathrm{A}$ group and the experimental $\mathrm{C}$ group, no GFP fluorescence deposits occurred in the rabbit bladders. The MOD values of GFP in the other organs were not significantly different $(P>0.05)$.

The MOD values of GFP in the four organs were not significantly different in the control B group $(P=0.085)$.

In the experimental D group, one-way ANOVA and Tamhane's T2 test (heterogeneity of variance, $P<0.05$ ) revealed that the MOD values of GFP in the four organs in rabbits were significantly different $(P<0.05)$. The MOD values of GFP in the oviduct were higher than in the uterus and liver $(P=0.038, P=0.012)$. The MOD values of GFP in the bladder were lower than in the liver $(P=0.024)$. The MOD values of GFP in the other organs were not significantly different $(P>0.05)$ (Table 3$)$.

Fluorescent colocalization of CK7 and WJMSCs in the oviduct CK7 immunofluorescence staining was performed on oviduct tissues to evaluate whether WJMSCs promoted damaged epithelial cell growth. The results demonstrated CK7-positive cells in the cytoplasm of tubal epithelium. 

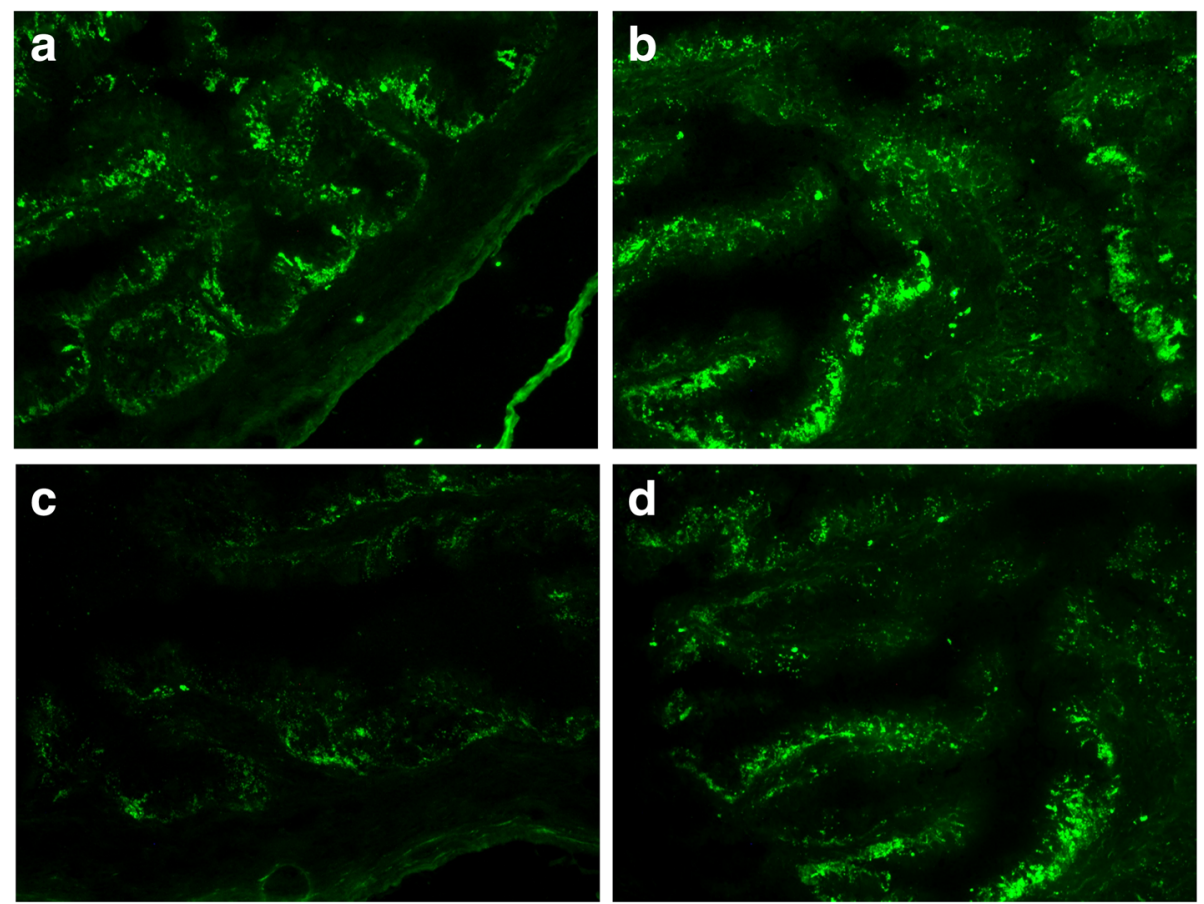

Fig. 2 GFP fluorescence deposits in the epithelia of the oviduct. a Control A group. b Control B group. c Experimental C group. d Experimental D group

The red fluorescence of CK7 overlapped with the green fluorescence of WJMSCs in tubal epithelium. Yellow fluorescence indicative of the colocalization of CK7 and WJMSCs was observed in all four groups, especially in the experimental D group. One-way ANOVA and the LSD test (homogeneity of variance, $P>0.05$ ) revealed that the MOD values of CK7 in tubal epithelium were significantly different $(P<0.05)$. The MOD values of CK7 in the experimental D group were higher than in the experimental $\mathrm{C}$ group and the control A group $(P=$ $0.000, P=0.000)$. The MOD values of CK7 in the control $B$ group were higher than in the experimental $C$ group and the control A group $(P=0.000, P=0.000)$. The MOD values of CK7 in the other groups were not significantly different $(P>0.05)$ (Fig. 6, Table 4$)$.

\section{Discussion}

Green fluorescent proteins and their variants and homologs of different colors are used in a variety of

Table 1 Cell proliferation ability in the transfer group and the untransfected group

\begin{tabular}{lllll}
\hline Group & $24 \mathrm{~h}(\mathrm{OD})$ & $48 \mathrm{~h}(\mathrm{OD})$ & $72 \mathrm{~h}(\mathrm{OD})$ & $96 \mathrm{~h}(\mathrm{OD})$ \\
\hline Transfer & $0.31 \pm 0.03$ & $0.42 \pm 0.02$ & $0.64 \pm 0.06$ & $1.01 \pm 0.06$ \\
Untransfected & $0.31 \pm 0.02$ & $0.40 \pm 0.01$ & $0.60 \pm 0.02$ & $0.94 \pm 0.05$ \\
$P$ & 0.683 & 0.107 & 0.213 & 0.069 \\
\hline
\end{tabular}

$O D$ optical density applications to investigate the organization and function of living systems [21]. A previous study used DiI, BrdU, and adenovirus-carrying GFP to label adipose-derived stem cells (ASCs), and the labeling efficiencies were compared at different time points and passages using fluorescence microscopy [22]. The results demonstrated that $100 \%$ and $90 \%$ of the ASCs emitted red fluorescence in the cytoplasm with no fluorescence in the nuclei $48 \mathrm{~h}$ after DiI and BrdU staining, respectively, but the fluorescence intensity declined quickly after cell passaging. Cell labeling with GFP adenovirus demonstrated a more stable labeling efficiency, and green fluorescence was detected $24 \mathrm{~h}$ after labeling. Greater than $90 \%$ of the ASCs remained positively stained without an obvious attenuation of fluorescence intensity 5 days later, even after cell passaging. Ma et al. [23] compared the efficiency of transfection of marrow stem cells using a lentiviral vector and an adenoviral vector. They found that the transfection efficiency of the BMP2 gene by lentivirus was significantly higher than that by adenovirus. It is worth noting that previous studies showed that GFP-carrying lentivirus had no adverse effect on the differentiation function and death rate of MSCs, laying the foundation for a valid method for the long term in vivo and in vitro [24-26]. Additionally, Tsai et al. [27] and $\mathrm{Yu}$ et al. [28] demonstrated that lentivirus-mediated transfection has no influence on the secretion function of MSCs. The transfection efficiency of WJMSCs transduced with 

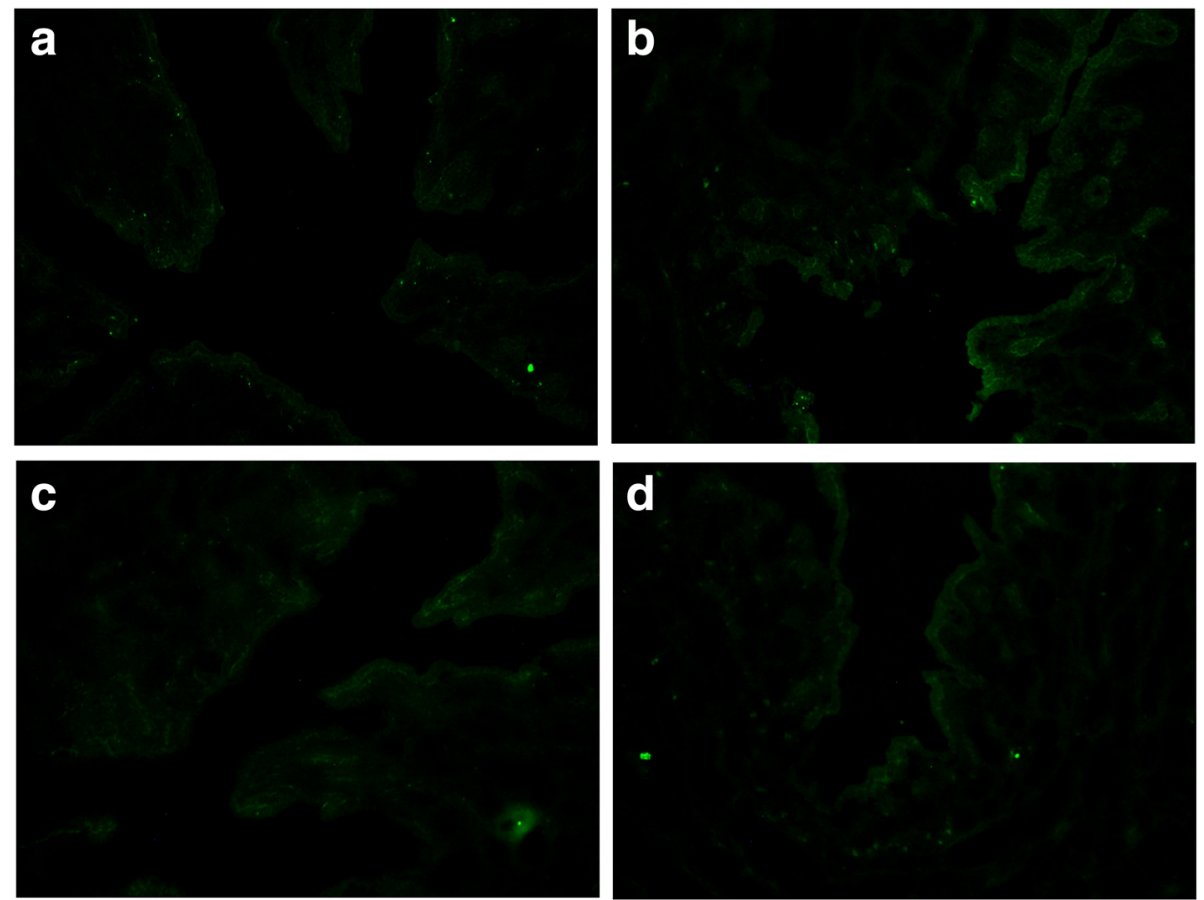

Fig. 3 GFP fluorescence deposits in the endometrium. a Control A group. b Control B group. c Experimental C group. d Experimental D group

LV3-GFP-PURO lentivirus was $96.7 \%$ in our study. The cell proliferation ability of WJMSCs in the transfer group and the untransfected group was not significantly different $(P>0.05)$, which is consistent with previous research [29]. These results demonstrated that lentivirus with the GFP gene was efficiently transfected and did not influence the proliferation ability of WJMSCs, within limits. Therefore, this method is applicable for labeling and tracking in vivo.

A recent study revealed that osteoblasts transfected with GFP using an adenovirus vector were expressed in vitro and were traceable in vivo. The authors found that the GFP was obviously expressed in nude mice at 4 and 8 weeks [30]. Another study injected neural stem cells with GFP into the paracelein of mice. The authors found that GFP fluorescence deposits occurred most significantly in the paracelein after 14 days. The
GFP fluorescence decreased gradually and finally disappeared [31]. Rabbits in the control group were injected with a $1 \times 10^{6} / \mathrm{ml}$ suspension of GFP-labeled WJMSCs once weekly for 3 weeks in our study. One week after the last perfusion, the oviduct, uterus, bladder, and liver were sampled for examination. We observed GFP in all four organs examined, especially in the oviduct in the experimental D group. However, we did not sample tissue after the last WJMSC perfusion, and we could not evaluate the long-term efficiency of GFP.

Gallatin et al. [32] first described lymphocyte homing to lymph nodes in vivo in 1983. MSC homing was defined subsequently as the arrest of MSCs within the vasculature of a tissue followed by transmigration across the endothelium. The exact mechanism of migration and homing characteristics of MSCs is still unknown.

Table 2 Mean optical density of GFP in different rabbit groups

\begin{tabular}{|c|c|c|c|c|c|}
\hline & & MOD & & & \\
\hline Group & $n$ & Oviduct & Uterus & Bladder & Liver \\
\hline Control A & 5 & $56.95 \pm 2.26$ & $40.03 \pm 22.78$ & $0.00 \pm 0.00$ & $80.62 \pm 13.49$ \\
\hline Control B & 5 & $62.45 \pm 3.93$ & $54.71 \pm 0.85$ & $49.34 \pm 2.40$ & $66.87 \pm 21.05$ \\
\hline Experimental C & 6 & $59.29 \pm 7.58$ & $37.22 \pm 28.85$ & $0.00 \pm 0.00$ & $69.43 \pm 3.50$ \\
\hline Experimental D & 6 & $82.94 \pm 14.37$ & $57.91 \pm 9.53$ & $51.86 \pm 6.45$ & $64.59 \pm 1.45$ \\
\hline F & & 10.549 & 1.633 & 368.295 & 1.843 \\
\hline P & & 0.000 & 0.217 & 0.000 & 0.176 \\
\hline
\end{tabular}

GFP green fluorescent protein, MOD mean optical density 

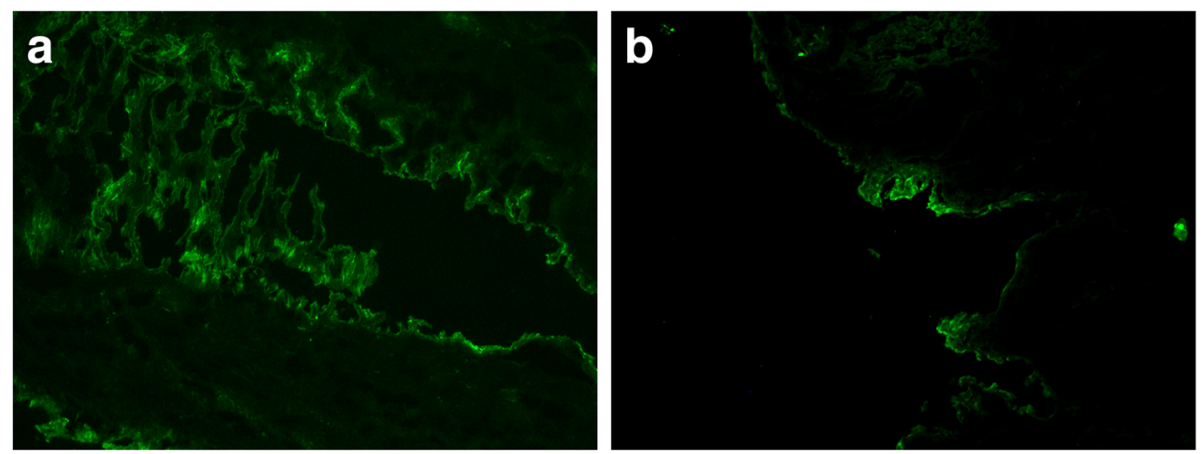

Fig. 4 GFP fluorescence deposits in the epithelia of the bladder. a Control B group. $\mathbf{b}$ Experimental D group

Worthy of note is that the influencing factors of homing characteristics, such as oxygen condition and some growth factors, were widely reported [33]. At present, some studies have shown that the mechanism may be decided by certain chemokines and their receptors [34]. Matrix metalloproteases (MMP) also play an important role in MSC migration [35]. Another important role is perfusion of MSCs. MSC therapy in clinics or experiments was often performed via intravascular injection with the hope that the cells would reach the lesion site through the circulation because of the homing function. However, previous studies of MSC homing reported that intravascular injections produced low MSC detection rates in target organs, which affected the curative effect of MSCs. Barbash et al. [36] found that systemic intravenous delivery of BM-MSCs to rats after myocardial infarction was limited by the entrapment of the donor cells in the lungs. Direct left ventricular cavity infusion enhanced the migration and colonization of the cells preferentially to the ischemic myocardium. In our study, the MOD values of GFP in the oviduct of the experimental $\mathrm{D}$ group were higher than those in the control A group and the experimental $C$ group $(P=0.037, P=$ $0.047)$. The MOD values of GFP in the oviduct of the experimental D group were higher than those in the control A group, but this difference was not statistically significant. In the experimental D group, the MOD values of GFP in the oviduct of rabbits were higher than in the uterus and liver $(P=0.038, P=0.012)$. These results suggest that the WJMSCs could home to the injured oviduct
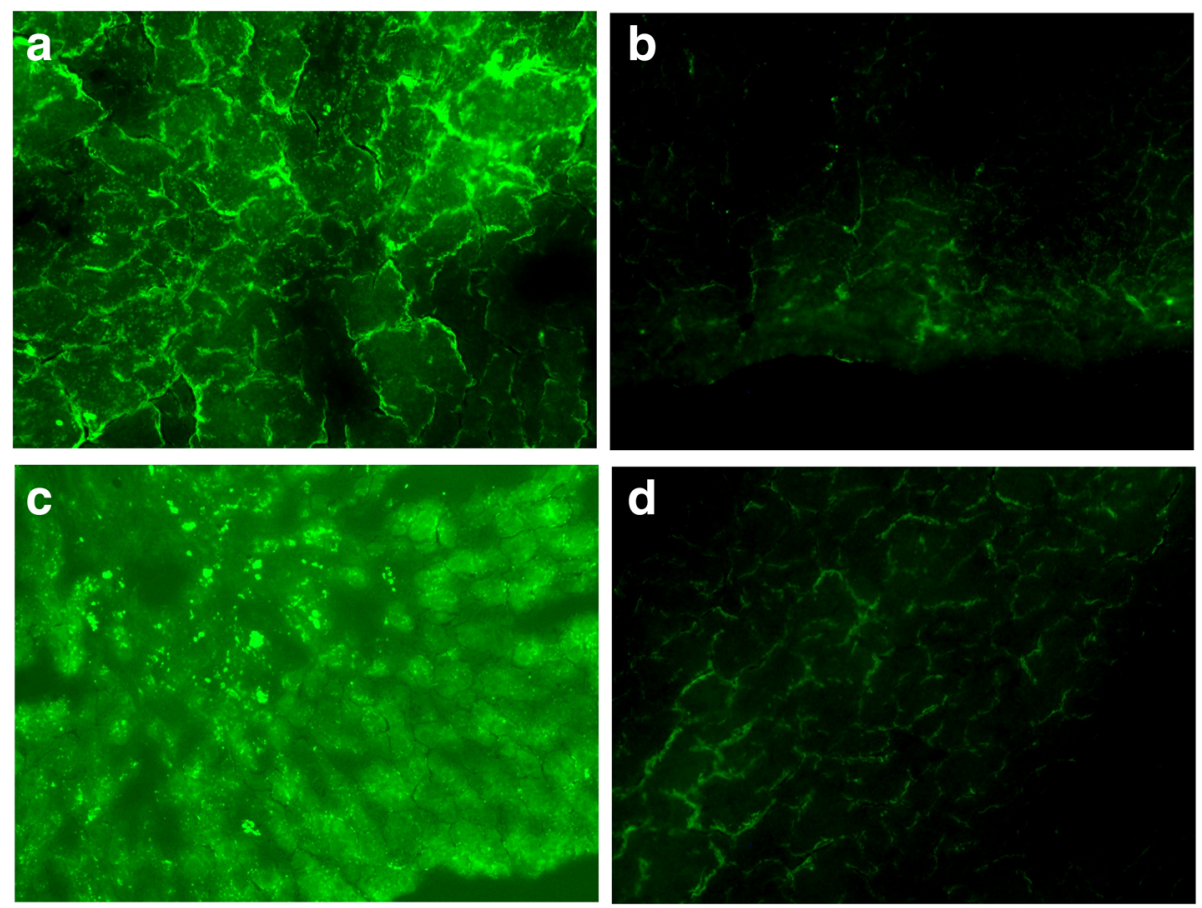

Fig. 5 GFP fluorescence deposits in hepatic cells. a Control A group. b Control B group. c Experimental C group. d Experimental D group 

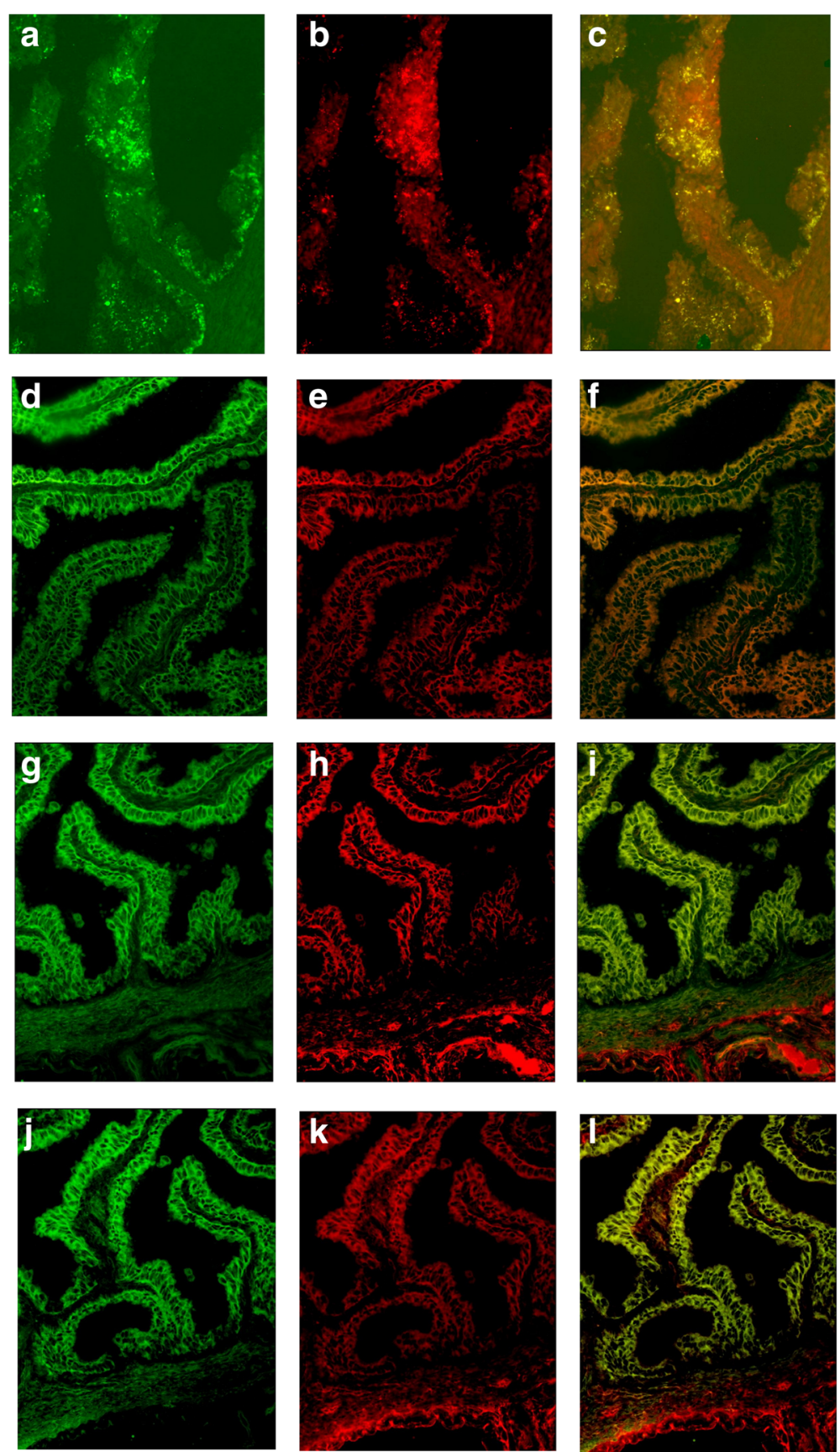

Fig. 6 CK7-positive staining in the cytoplasm. Observed red fluorescence of CK7 overlapped with green fluorescence of WJMSCs with GFP in tubal epithelium. Yellow fluorescence of colocalization of CK7 and WJMSCs observed in all four groups. a-c Control A group. $\mathbf{d}-\mathbf{f}$ Control B group. g-i Experimental C group. $\mathbf{j}-\mathbf{I}$ Experimental D group

with limited efficiency. The efficiency was influenced by the perfusion method (e.g., artery, vein, or local perfusion), age, and passage number of the cells, and culture conditions [37]. Vaginal local perfusion provided direct contact of WJMSCs with injured tubal epithelium. The injured tubal epithelium may secrete chemotactic factors and adhesion molecules to attract WJMSCs to colonize and play a role in repair. This method may reduce the delay of
WJMSCs that was observed in other organs or tissues. Our results demonstrated that future applications of WJMSCs should incorporate local or injury application as the preferred method to increase healing effectiveness.

A previous study directly injected isolated MSCs into adult mouse hearts, and MSCs were detected in the lung, small intestine, and stomach [38]. This study demonstrated that MSCs homed to injured sections 
Table 3 Mean optical density of GFP in different organs

\begin{tabular}{lllll}
\hline Organ & $\begin{array}{l}\text { Control } \\
\text { A group } \\
(n=5)\end{array}$ & $\begin{array}{l}\text { Control } \\
\text { B group } \\
(n=5)\end{array}$ & $\begin{array}{l}\text { Experimental } \\
\text { C group } \\
(n=6)\end{array}$ & $\begin{array}{l}\text { Experimental } \\
\text { D group } \\
(n=6)\end{array}$ \\
\hline Oviduct & $56.95 \pm 2.26$ & $62.45 \pm 3.93$ & $59.29 \pm 7.58$ & $82.94 \pm 14.37$ \\
Uterus & $40.03 \pm 22.78$ & $54.71 \pm 0.85$ & $37.22 \pm 28.85$ & $57.91 \pm 9.53$ \\
Bladder & $0.00 \pm 0.00$ & $49.34 \pm 2.40$ & $0.00 \pm 0.00$ & $51.86 \pm 6.45$ \\
Liver & $80.62 \pm 13.49$ & $66.87 \pm 21.05$ & $69.43 \pm 3.50$ & $64.59 \pm 1.45$ \\
$F$ & 32.665 & 2.635 & 25.164 & 12.746 \\
$P$ & 0.000 & 0.085 & 0.000 & 0.000 \\
\hline
\end{tabular}

GFP green fluorescent protein

and reached normal tissues. Our study injected WJMSCs into female rabbits in control and experimental groups via the ear vein and/or genital tract perfusion. The WJMSCs were found in the injured oviduct and the normal tissues (e.g., uterus, livers, bladder). No GFP fluorescence deposits occurred in the bladder of the control A group or experimental $\mathrm{C}$ group. The MOD values of GFP in the uterus in the control $B$ group and the experimental $\mathrm{D}$ group were higher than in the control A group and the experimental $\mathrm{C}$ group, but this difference was not statistically significant $(P=$ 0.217). These results demonstrated that the local injection of WJMSCs increased colonization in organs near the genital tract. However, the detailed mechanism requires further future research. The MOD values of GFP in the bladder were lower than in the liver in the control A group, the experimental $\mathrm{C}$ group, and the experimental D group $(P=0.000, P=0.000, P=0.024)$. This trend suggests that the liver, which is an organ with more blood flow than the bladder, may attract more WJMSCs. Additionally, although without significant difference, the MOD values of GFP in the livers of the control A group and the experimental $\mathrm{C}$ group, which included vein injections, were higher, especially in the control A group, than in the control B group and the experimental $\mathrm{D}$ group. This result suggests that future applications of WJMSCs via blood vessel perfusion would reduce the retention volume of WJMSCs in other normal organs, especially organs with a rich blood flow, which is very important.
Epithelial tissues of the oviduct play a very important role in reproductive processes. Cytokeratin is a special marker in the epithelial tissue of the female genital tract. It is a member of the cytoskeleton that provides crucial mechanical support $[39,40]$. Many studies used cytokeratin to identify primary epithelial cells. The epithelial cells in the oviduct express CK7 [41]. It is known that WJMSCs express pan-cytokeratin but not CK7 [42]. Our research showed that colocalization of CK7 and WJMSCs was observed in tubal epithelium in all four groups, especially in the experimental D group. From the colocalization picture we could see that WJMSCs/CK7 appeared alone or overlapped with the other. This result suggested that parts of new epithelial cells in the oviducts were differentiated from parts of transplanted WJMSCs in our study. Additionally, the MOD values of CK7 in tubal epithelium were significantly different in the four groups $(P<0.05)$. The MOD values of $C K 7$ in the experimental $D$ group were higher than those in the experimental $C$ group $(P=0.000)$. The MOD values of CK7 in the control B group were higher than in the control A group $(P=0.000)$. These results demonstrated that vaginal local transplantation of WJMSCs into oviduct epithelium was easier to promote epithelial cell growth. The mechanism of inflammation therapy of WJMSCs may be divided into two parts. First, WJMSCs differentiated into epithelial cells directly. This mechanism was demonstrated in previous studies $[43,44]$. Second, WJMSCs also promoted epithelial cell growth via a secretion function, such as increased secretion of IL-10, and the inhibitory effect of proinflammatory factors improved the microenvironment of injured sections $[45,46]$.

\section{Limitation}

Although the main purpose of our study was to trace WJMSCs in vivo via using a chronic salpingitis model, we have not confirmed the survival time and secretion function of WJMSCs after engraftment. In our further study, this field will be the main problem to be solved. Additionally, an antibiotic medication group could be better to compare the therapeutic effect of WJMSCs. Furthermore, GFP sliders without DAPI are a main drawback of our study. Another major limitation of this study was that the sample size was ultimately not large

Table 4 Mean optical density of CK7 in rabbit tubal epithelium

\begin{tabular}{lllll}
\hline Group & $n$ & CK7 MOD & $\begin{array}{l}\text { Compared with respective control group } \\
\text { P1 }\end{array}$ & $\begin{array}{l}\text { Compared with experimental group } \\
\text { P2 }\end{array}$ \\
\hline Control A & 5 & $49.73 \pm 1.60$ & & \\
Control B & 5 & $61.31 \pm 1.75$ & & \\
Experimental C & 6 & $50.50 \pm 4.82$ & 0.745 & 0.000 \\
Experimental D & 6 & $66.22 \pm 5.17$ & 0.052 & \\
\hline
\end{tabular}

$F=24.683, P=0.000$

CK7 cytokeratin 7, MOD mean optical density 
enough to obtain a significant difference. Therefore, further investigation is currently underway with a larger sample size.

\section{Conclusion}

Lentivirus with a GFP gene was an efficient transfection agent that did not influence the proliferation ability of WJMSCs within limits. This method is applicable for labeling and tracking in vivo. Notably, WJMSCs exhibited homing characteristics and migrated to the injured oviduct to promote epithelial cell growth. The transplanted WJMSCs could differentiate into epithelial cells. Local treatment provided higher efficiency.

\section{Abbreviations}

ASC: Adipose-derived stem cell; GFP: Green fluorescent protein; HCG: Human chorionic gonadotropin; MHC: Main histocompatibility complex; MMP: Matrix metalloproteases; MOD: Mean optical density; MSC: Mesenchymal stem cell; WJMSC: Wharton's jelly-derived mesenchymal stem cell

\section{Acknowledgements}

Not applicable

\section{Funding}

This experiment was funded by the National Natural Science Foundation of China (\#81370676), the Guangdong Provincial Department of Science and Technology (\#2012B32000007039), and the Guangzhou City Department of Science and Technology (\#7411785665675).

\section{Availability of data and materials}

The datasets used and/or analyzed during the current study are available from the corresponding author on reasonable request.

\section{Authors' contribution}

$X-M X, Z L$, and ZZ conceived and designed the experiments. ZL, ZZ, W-KM, $X C$, and $X-M X$ performed the experiments. $W-K M, Z L$, and $Z Z$ analyzed the data. W-KM and XC contributed reagents/materials/analysis tools. ZL and ZZ wrote the paper. All authors read and approved the final manuscript.

\section{Ethics approval and consent to participate}

This study was approved by the Ethics Committee of the 1st Affiliated Hospital of Jinan University and run in accordance with the guidelines of the Helsinki Declaration. All participants provided written informed consent to participate in this study. All of the WJMSCs in our study were manufactured and provided by the Cord Blood Bank of Guangdong Province of China. All female New Zealand rabbits were provided by the Animal Experiment Center of Guangzhou University of Chinese Medicine (qualification no. CV20130015). The Institutional Animal Research Ethics Review Board of Guangzhou University of Chinese Medicine approved the animal experimental protocol. Animals were used in accordance with the Animal Care and Use Committee of Jinan University.

\section{Consent for publication}

Not applicable

\section{Competing interests}

The authors declare that they have no competing interests.

\section{Publisher's Note}

Springer Nature remains neutral with regard to jurisdictional claims in published maps and institutional affiliations.

\section{Author details}

'The Department of Obstetrics and Gynecology, 1st Affiliated Hospital of Jinan University, Guangzhou 510000, China. ${ }^{2}$ The Department of Reproduction, Southern Medical University Affiliate Dongguan People's
Hospital, Dongguan, China. ${ }^{3}$ Harvard Medical School, Harvard University, Boston, MA, USA.

Received: 3 August 2017 Revised: 22 September 2017 Accepted: 26 October 2017 Published online: 01 December 2017

\section{References}

1. Dun EC, Nezhat CH. Tubal factor infertility: diagnosis and management in the era of assisted reproductive technology. Obstet Gynecol Clin North Am. 2012;39(4):551-66

2. Friedenstein AJ, Latzinik NW, Grosheva AG, Gorskaya UF. Marrow microenvironment transfer by heterotopic transplantation of freshly isolated and cultured cells in porous sponges. Exp Hematol. 1982;10(2):217-27.

3. Tan X, Gong YZ, WU P, Liao DF, Zheng XL. Mesenchymal stem cell-derived microparticles: a promising therapeutic strategy. Int J Mol Sci. 2014;15(8): 14348-63.

4. Lu LL, Liu YJ, Yang SG, Zhao QJ, Wang X, Gong W, et al. Isolation and characterization of human umbilical cord mesenchymal stem cells with hematopoiesis-supportive function and other potentials. Haematologica. 2006;91(8):1017-26.

5. Gnoth C, Godehardt E, Frank-Herrmann P, Friol K, Tigges J, Freundl G. Definition and prevalence of subfertility and infertility. Hum Reprod Hum Reprod. 2005;20(5):1144-7.

6. Cohen TS, Prince AS. Activation of inflammasome signaling mediates pathology of acute $P$. aeruginosa pneumonia. J Clin Invest. 2013;123(4): 1630-7.

7. Weiss ML, Medicetty S, Bledsoe AR, Rachakatla RS, Choi M, Merchav S, et al. Human umbilical cord matrix stem cells: preliminary characterization and effect of transplantation in a rodent model of Parkinson's disease. Stem Cells. 2006;24(3):781-92.

8. Karahuseyinoglu S, Cinar O, Kilic E, Kara F, Akay GG, Demiralp DO, et al. Biology of stem cells in human umbilical cord stroma: in situ and in vitro surveys. Stem Cells. 2007;25(2):319-31.

9. Conconi MT. CD105(+) cells from Wharton's jelly show in vitro and in vivo myogenic differentiative potential. Int J Mol Med. 2006;18(6):1089-96.

10. Leow SN, Luu CD, Hairul Nizam MH, Mok PL, Ruhaslizan R, Wong HS. Safety and efficacy of human Wharton's jelly-derived mesenchymal stem cells therapy for retinal degeneration. PLoS One. 2015;10(6):e0128973.

11. Shi S, Zhang M, Guo R, Miao Y, Zhang M, Hu J, et al. Feasibility of lentiviralmediated sodium iodide symporter gene delivery for the efficient monitoring of bone marrow-derived mesenchymal stem cell transplantation and survival. Int J Mol Med. 2014;34(6):1547-54.

12. Liu S, Yuan M, Hou K, Zhang L, Zheng X, Zhao B, et al. Immune characterization of mesenchymal stem cells in human umbilical cord Wharton's jelly and derived cartilage cells. Cell Immunol. 2012;278(1-2):35-44.

13. Medicetty S, Bledsoe AR, Fahrenholtz CB, Troyer D, Weiss ML. Transplantation of pig stem cells into rat brain: proliferation during the first 8 weeks. Exp Neurol. 2004;190(1):32-41.

14. Li Z, Zhang Z, Chen X, Zhou J, Xiao XM. Treatment evaluation of Wharton's jelly-derived mesenchymal stem cells using a chronic salpingitis model: an animal experiment. Stem Cell Res Ther. 2017;8(1):232.

15. Luo HJ, Xiao XM, Zhou J, Wei W. Therapeutic influence of intraperitoneal injection of Wharton's jelly-derived mesenchymal stem cells on oviduct function and fertility in rats with acute and chronic salpingitis. Genet Mol Res. 2015;14(2):3606-17.

16. Kunter U, Rong S, Boor P, Eitner F, Müller-Newen G, Djuric Z, et al. Mesenchymal stem cells prevent progressive experimental renal failure but maldifferentiate intoglomerular adipocytes. J Am Soc Nephrol. 2007;18(6): 1754-64.

17. Tögel F, Cohen A, Zhang P, Yang Y, Hu Z, Westenfelder C. Autologous and allogeneic marrow stromal cells are safe and effective for the treatment of acutekidney injury. Stem Cells Dev. 2009;18(3):475-85.

18. Choi S, Park M, Kim J, Hwang S, Park S, Lee Y. The role of mesenchymal stem cells in the functional improvement of chronic renal failure. Stem Cells Dev. 2009;18(3):521-9

19. Zhang W, Qin C, Zhou ZM. Mesenchymal stem cells modulate immune responses combined with cyclosporine in a rat renal transplantation model. Transplant Proc. 2007;39(10):3404-8.

20. Semedo P, Correa-Costa M, Antonio Cenedeze M, Maria Avancini Costa Malheiros D, Antonia dos Reis M, Shimizu MH, et al. Mesenchymal stem 
cells attenuate renal fibrosis through immune modulation and remodeling properties in a rat remnant kidney mode. Stem Cells. 2009;27(12):3063-73.

21. Chudakov DM, Matz MV, Lukyanov S, Lukyanov KA. Fluorescent proteins and their applications in imaging living cells and tissues. Physiol Rev. 2010; 90(3):1103-63

22. Li KC, Chang Q, Lu F. Comparison of the efficiency of three techniques for labeling human adipose-derived stem cells. Nan Fang Yi Ke Da Xue Xue Bao. 2011;31(4):582-6.

23. Ma XS, Jiang JY, Lü FZ, Ma X, Li XK, Huang HY. Transduction of recombinant marrow stem cells using lentiviral vector and adenoviral vector: a comparative study. Zhonghua Yi Xue Za Zhi. 2006;86(47):3340-4.

24. Chang J, Tang L, Lei H, Zhang XG, Zuo Z, Huang W, et al. Effects of lentiviral infection of mesenchymal stem cells on the expression of octamertranscription factor 4. Mol Med Rep. 2014;10(5):2249-54.

25. Tao R, Sun TJ, Han YQ, Xu G, Liu J, Han YF. Optimization of in vitro cell labeling methods for human umbilical cord-derived mesenchymalstem cells. Eur Rev Med Pharmacol Sci. 2014;18(8):1127-34.

26. Lisa MG, Jill MM, Padraig S, Frank B, Mary M, Daniel OT, et al. Lentiviral vector mediated modification of mesenchymal stem cells \& enhanced survival in an invitro model of ischaemia. Stem Cell Res Ther. 2011;2(2):12.

27. Tsai PJ, Wang HS, Lin GJ, Chou SC, Chu TH, Chuan WT, et al. Undifferentiated Wharton's jelly mesenchymal stem cell transplantation induces insulin-producing cell differentiation and suppression of T-cellmediated autoimmunity in nonobese diabetic mice. Cell Transplant. 2015; 24(8):1555-70.

28. Yu J, Su X, Zhu C, Pan Q, Yang J, Ma J, et al. GFP labeling and hepatic differentiation potential of human placenta-derived mesenchymal stem cells. Cell Physiol Biochem. 2015;35(6):2299-308.

29. Tang $L$, Chang J. Effect of GFP-containing lentivirus infection on the expression of octamer transcription factor 4 in human umbilical cord mesenchymal stem cells. Xi Bao Yu Fen Zi Mian Yi Xue Za Zhi. 2013;29(3):292-6.

30. Ren GH, Liu XJ, Yang L, Pei GX. Study of osteoblasts transfected with gfp in vitro and traced in vivo. Zhonghua Zheng Xing Wai Ke Za Zhi. 2004;20(6): 439-42.

31. Tan X-j, Hu C-I, Wen-qin C. Green fluorescent protein as a marker of neural stem cells. Acta Acad Med Mil Tert. 2006;28(7):691-3.

32. Gallatin WM, Weissman IL, Butcher EC. A cell-surface molecule involved in organ-specific homing of lymphocytes. 1983. J Immunol. 2006;177(1):5-9.

33. Ryu CH, Park SA, Kim SM, Lim JY, Jeong CH, Jun JA, et al. Migration of human umbilical cord blood mesenchymal stem cells mediated by stromal cell-derived factor-1/CXCR4 axis via Akt, ERK, and p38 signal transduction pathways. Biochem Biophys Res Commun. 2010;398:105-10.

34. Hocking AM. The role of chemokines in mesenchymal stem cell homing to wounds. Adv Wound Care (New Rochelle). 2015;4(11):623-30.

35. Ries C, Egea V, Karow M, Kolb H, Jochum M, Neth P. MMP-2, MT1-MMP, and TIMP-2 are essential for the invasive capacity of human mesenchymal stem cells: differential regulation by inflammatory cytokines. Blood. 2007;109: 4055-63.

36. Barbash IM, Chouraqui P, Baron J, Feinberg MS, Etzion S, Tessone A, et al. Systemic delivery of bone marrow-derived mesenchymal stem cells to the infarcted myocardium: feasibility, cell migration, and body distribution. Circulation. 2003;108(7):863-8.

37. Sohni A, Verfaillie CM. Mesenchymal stem cells migration homing and tracking. Stem Cells Int. 2013;2013:130763.

38. Gojo S, Gojo N, Takeda Y, Mori T, Abe H, Kyo S, et al. In vivo cardiovasculogenesis by direct injection of isolated adult mesenchymal stem cells. Exp Cell Res. 2003;288(1):51-9.

39. Bragulla $\mathrm{HH}$, Homberger DG. Structure and functions of keratin proteins in simple, stratified, keratinized and cornified epithelia. J Anat. 2009;214:516-59.

40. Moll R, Divo M, Langbein L. The human keratins: biology and pathology. Histochem Cell Biol. 2008;129:705-33.

41. Lee H, Ro JY. Differential expression of GSK3 $\beta$ and pS9GSK3 $\beta$ in normal human tissues: can pS9GSK3 $\beta$ be an epithelial marker? Int J Clin Exp Pathol. 2015;8(4):4064-73.

42. Yang JM, Hao WJ, Liang YR, Wang GY, Li JX. Study on differentiation of human umbilical cord-derived mesenchymal stem cells into human sweat gland cells in vitro and the relative signal pathway. Zhonghua Shao Shang Za Zhi. 2011;27(4):265-8.
43. Koh SH, Kim KS, Choi MR, Jung KH, Park KS, Chai YG, et al. Imp lantation of human umbilical cord-derived mesenchymal stem cells as a neuroprotective therapy for ischemic stroke in rats. Brain Res. 2008;12(29):233-48.

44. Ding DC, Shyu WC, Chiang MF, Lin SZ, Chang YC, Wang HJ, et al. Enhancement of neuroplasticity through upregulation of beta1-integrin in human umbilical cord-derived stromal cell implanted stroke model. Neurobiol Dis. 2007;27(3):339-53.

45. Gonzalez-Rey E, Anderson P, González MA, Rico L, Büscher D, Delgado M. Human adult stem cells derived from adipose tissue protect against experimental colitis and sepsis. Gut. 2009;58(7):929-39.

46. Wang H, Yang YF, Zhao L, Xiao FJ, Zhang QW, Wen ML, et al. Hepatocyte growth factor gene-modified mesenchymal stem cells reduce radiationinduced lung injury. Hum Gene Ther. 2013;24(3):343-53.

\section{Submit your next manuscript to BioMed Central and we will help you at every step:}

- We accept pre-submission inquiries

- Our selector tool helps you to find the most relevant journal

- We provide round the clock customer support

- Convenient online submission

- Thorough peer review

- Inclusion in PubMed and all major indexing services

- Maximum visibility for your research

Submit your manuscript at www.biomedcentral.com/submit
Biomed Central 